\title{
Sol-Gel Encapsulation as Matrix for Potentiometric Nitrite-Selective Membranes Doped with Chloro (5, 10, 15, 20-Tetraphenylporphyrinato) Cobalt (III)
}

\author{
Hao Zhou ${ }^{\dagger \dagger}$, Mark E. Meyerhoff ${ }^{\dagger}$ Kai-shun $\mathrm{Bi}^{\dagger \dagger}$, and Sung Bae Park* \\ Department of Chemistry, Inje University, Kimhae 621-749, Korea \\ ${ }^{\dagger}$ Department of Chemistry, University of Michigan, Ann Arbor, MI 48109, USA \\ ${ }^{\dagger}$ School of Pharmacy, Shenyang Pharmaceutical University, Shenyang 110016, PR China
}

(Received October 25, 2009 : Accepted November 23, 2009)

\begin{abstract}
Organic-inorganic hybrid sol-gel matrices were used as hosts for chloro $(5,10,15,20$-tetraphenylporphyrinato) cobalt (III) $(\mathrm{Co}[\mathrm{TPP}] \mathrm{Cl})$, a known ionophore for nitrite. The sol-gel precursor was prepared by the reaction of (3-isocyanopropyl) triethoxysilane with 1,4-butanediol. An appropriate amount of the anion-exchanger, tridodecylmethylammonium chloride (TDMAC) and the plasticizer, tributylphosphate (DBP) were used as membrane additives. On mixing with an acidic catalyst, the sol-state precursors slowly gelled, yielding a membrane in which the active components, $\mathrm{Co}[\mathrm{TPP}] \mathrm{Cl}$ and TDMAC, were encapsulated. The performances of the sol-gel membrane-based electrodes were compared to those of $\mathrm{Co}$ [TPP]Cl-based poly(vinyl chloride) (PVC) membrane electrodes. Membranes with a molar ratio of Co[TPP]Cl: TDMAC $(1: 0.1)$ showed reasonable response slopes toward nitrite. The response slopes were typically $53 \mathrm{mV} /$ decade between $10^{-5.4}$ and $10^{-1.0} \mathrm{M}$. Selectivities toward nitrite over hydrophilic and small anions such as chloride were somewhat inferior to those observed with PVC-based membranes, but selectivities over lipophilic anions were quite similar. Reduced asymmetry potentials due to protein adsorption were found to occur with the sol-gel matrix relative to PVC-based films when the sensors were employed as a detector in flow-through configuration.
\end{abstract}

Keywords : Anion-Selective membrane electrode, $\mathrm{Co}[\mathrm{TPP}] \mathrm{Cl}$, Sol-Gel method, Asymmetry potential, Nitrite

\section{Introduction}

Since $\mathrm{Mn}(\mathrm{III})$-porphyrins were first reported as membrane active components in PVC-based membrane electrodes, ${ }^{1,2)}$ a wide variety of different metalloporphyrins have been employed as ionophores to induce useful selectivities toward given anions. For example, $\mathrm{Mn}(\mathrm{III}){ }^{3)} \mathrm{Sn}(\mathrm{IV}),{ }^{4,5)} \mathrm{In}(\mathrm{IIII}),{ }^{6} \mathrm{Ru}(\mathrm{III}),{ }^{7)} \mathrm{Co}(\mathrm{IIII}),{ }^{8,9)}$ and $\mathrm{Zr}(\mathrm{IV})^{10)}$ porphyrins have been employed to create anion sensors for thiocyanate, salicylate, chloride, thiocyanate, nitrite and fluoride, respectively. Thanks to efforts to elucidate the reaction mechanisms of the ionophores within the membrane, a dimer-monomer

*E-mail: chempsb@inje.ac.kr mechanism has been found to responsible for the super-Nerntian response behavior found with $\mathrm{Ga}(\mathrm{III})$ and In(III) porphyrin-based membrane electrodes. ${ }^{11)}$ In addition, through a systematic study using lipophilic anionic and cationic additives, researchers were able to conclude that $\mathrm{Co}(\mathrm{III})$-porphrins behave as electrically neutral carriers that exhibit almost Nerntian response toward nitrite anion. ${ }^{8)}$

As a matrix, PVC is by far the most commonly used polymer for preparation of such membrane electrodes. A plasticizer, such as o-nitrophenyl octyl ether (NPOE) is also employed to formulate such sensing films. However, in many cases, these electrodes not only show poor selectivities over salicylate and other lipophilic organic anions, but also 
exhibit clotting and fouling effects from blood proteins in clinical applications (e.g., asymmetry potentials due to strong protein adsorption to the surface of the membranes). Many scientists have studied the effects of matrices other than PVC on the performance of membrane electrodes. For example, Oka et al. suggested the use of a polystyrene membrane with covalently bound quaternary ammonium sites for anion sensing especially for chloride. ${ }^{12)}$ Park et al. reported the use of an asymmetric cellulose triacetate (CTA) membrane matrix. This research group employed newly developed chloride ionophores, In(III) porphyrins, in conjunction with a flow-injection system to minimize nonspecific adsorption of proteins in human serum samples for chloride measurements. ${ }^{6)}$ Although the method also showed improvements in terms of chloride selectivity, the approach may be difficult to implement in practical applications (i.e., in developing membranes on top of solid-state electrodes).

Considerable attention has been focused on the solgel encapsulation method for the preparation of matrices in various fields. ${ }^{13)}$ For example, biosensor applications of sol-gel matrices have been reported often because of their three-dimensional rigidity and encapsulation properties. ${ }^{14,15)}$ Modified sol-gel methods have been also reported for the preparation of different cation and anion-selective electrodes. ${ }^{16)}$ After initial reports of chloride-selective electrodes employing the solgel method, ${ }^{17,18)}$ the possibility of using a traditional carbonate-selective ionophore, trifluoroacetyl- $p$-decylbenzene (TFADB), within a sol-gel matrix has also been studied. ${ }^{19)}$

In the present paper, we report the applicability of the sol-gel matrix in conjunction with $\mathrm{Co}[\mathrm{TPP}] \mathrm{Cl}$, which is known as a neutral carrier ionophore for nitrite. ${ }^{8,9)}$ Nitrite plays important roles in biological and environmental areas. That is, nitrite is a precursor in the formation of carcinogenic N-nitrosamines. ${ }^{20)}$ Also nitrite is a reaction product between $\mathrm{NO}$, an atmospheric pollutant, with water and oxygen. ${ }^{21)}$ Although nitrite can be measured by ion-exchange chromatography and spectrophotometric methods, ${ }^{22}$ electrochemical and/or optical sensor systems have been of considerable interest $^{23)}$ owing to their low cost and simplicity. Herein, we report the response properties of $\mathrm{Co}$ [TPP]Cl-doped sol-gel membranes toward nitrite and contrast their behavior vs. a conventional PVC matrix formulated with the same ionophore.

\section{Experimental Section}

\section{Reagents}

The ionophore, $\mathrm{Co}[\mathrm{TPP}] \mathrm{Cl}$ was synthesized via metallation of the free porphyrin obtained from Midcentury (Posen, IL) and $\mathrm{CoCl}_{3}$ from Aldrich (St. Louis, MO) by refluxing in glacial acetic acid. ${ }^{24)} \mathrm{PVC}$, tridodecylmethylammonium chloride (TDMAC), (3-isocyanopropyl)triethoxysilane were purchased from Fluka (Buch, Switzerland). 1,4-Butanediol and tetrahydrofuran (THF) were obtained from Aldrich (Milwaukee, WI) and were purified over calcium hydride and sodium, respectively. A buffer solution consisting of $0.05 \mathrm{M}$ 4-morpholinoethanesulfonic acid (MES), adjusted to $\mathrm{pH} 5.5$ with sodium hydroxide was used as the working buffer for all potentiometric measurements. Bovine serum albumin (BSA) was a product of Sigma Chemical Co.(St. Louis, MO). Before use, the BSA was first dialyzed against the MES buffer for three days with fresh buffer changes every $12 \mathrm{~h}$. All other chemicals used were analytical-reagent grade. Standard solutions were prepared with deionized water (resistivity, $18 \mathrm{M} \Omega \cdot \mathrm{cm})$.

\section{Polymer Membranes and Electrodes}

The sol-gel precursor was prepared by the reaction of 1,4-butanediol (1) and (3-isocyanopropyl)triethoxysilane (2) (stoichiometric ratio $\mathrm{NCO} / \mathrm{OH}=1$ ) in THF(see Fig. 1). The reaction mixture was refluxed for $24 \mathrm{~h}$ under a nitrogen atmosphere. After evaporation

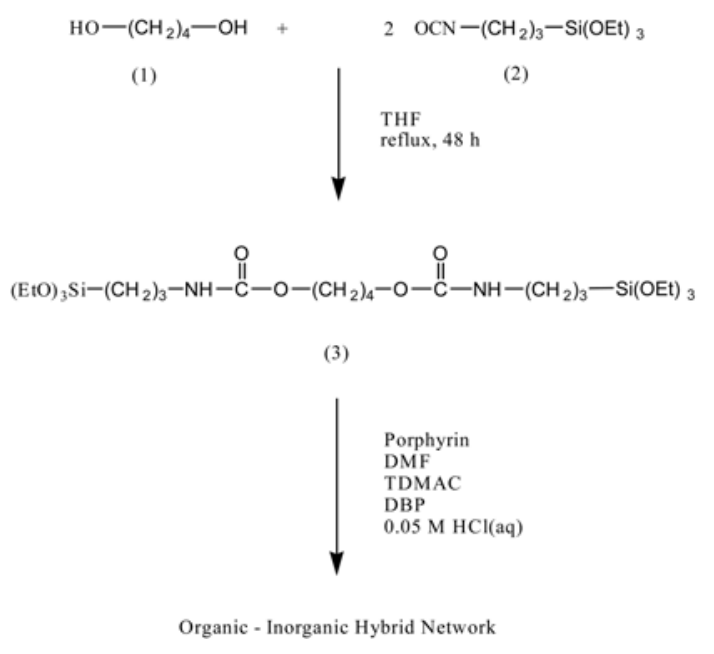

Fig. 1. A scheme for a low-temperature sol-gel process for an organic-inorganic polymer network containing Co[TPP]CI and TDMAC. 
Table 1. Formulation of different nitrite selective membranes from the sol-gel and the traditional method

\begin{tabular}{cccccc}
\hline membrane ID* & Co[TPP]Cl & plasticizer & matrix & solvent & $\begin{array}{c}\text { TDMAC/Co[TPP] } \\
\text { Clmol ratio }\end{array}$ \\
\hline SG-10\% & $3.0 \mathrm{mg}$ & DBP $20 \mu \mathrm{L}$ & $150 \mathrm{mg}$ & $0.8 \mathrm{~mL} \mathrm{DMF}$ & 0.1 \\
SG-0\% & $3.0 \mathrm{mg}$ & DBP $20 \mu \mathrm{L}$ & $150 \mathrm{mg}$ & $0.8 \mathrm{~mL} \mathrm{DMF}$ & 0 \\
PVC-10\% & $1.5 \mathrm{mg}$ & NPOE $100 \mathrm{mg}$ & $50 \mathrm{mg}$ & $1.5 \mathrm{~mL} \mathrm{THF}$ & 0.1 \\
\hline
\end{tabular}

*PVC- $10 \%$ and SG-10\% denote PVC-and sol-gel-based membrane electrodes containing $10 \mathrm{~mol} \%$ of TDMAC to the metalloporphyrin, respectively. SG- $0 \%$ denotes sol-gel based membrane electrodes containing no TDMAC.

of the THF, the viscous sol-state precursor (1,4-precursor, 3) was dissolved in N,N-dimethylformamide with $\mathrm{Co}[\mathrm{TPP}] \mathrm{Cl}$, TDMAC and DBP according to the formulation shown in Table 1. After shaking the mixture for 1 min., $15 \mu \mathrm{L}$ of $0.05 \mathrm{M}$ hydrochloric acid was added. After shaking the mixture for another $30 \mathrm{~s}$, the mixture was poured onto a boat $(1.4 \times 1.4 \mathrm{~cm})$ of poly(ethylene terephthalate) film. The polymerization was carried out at $40^{\circ} \mathrm{C}$ for $48 \mathrm{~h}$ to obtain transparent gels that contain the ionophore and the ion-exchanger. Before use, the gel membrane was vacuum-dried at $40^{\circ} \mathrm{C}$ for $24 \mathrm{~h}$. PVC-based membranes were prepared according to the method of Simon and co-workers. ${ }^{25}$ ) After the membranes were allowed to cure, 5.5-mmdiameter disks were cut out and placed in Phillips electrode bodies (ISE-561, Glasblaserei Möller, Zürich, Switzerland). As an internal filling solution, $0.01 \mathrm{M}$ $\mathrm{NaNO}_{2} / 0.1 \mathrm{M} \mathrm{NaCl}$ solution was used.

\section{Static Mode Potentiometric Measurements}

Cell potentials were measured at an ambient temperature of $22( \pm 2)^{\circ} \mathrm{C}$. The cell used was as follows: $\mathrm{Ag} / \mathrm{AgCl}(\mathrm{s}) / 4 \mathrm{M} \mathrm{KCl}$ saturated with $\mathrm{AgCl} / \mathrm{MES}$ buffer/sample solution/ion-selective membrane/internal filling solution/ $\mathrm{AgCl}(\mathrm{s}) / \mathrm{Ag}$. Potential differences between the membrane electrodes and the Fisher double-junction $\mathrm{Ag} / \mathrm{AgCl}$ reference electrode were measured using a computer equipped with a high-impedance input 8-channel A/D converter (Kosentech, Model KST101, Busan, Korea) with a sample rate of $1 \mathrm{~Hz}$. This apparatus was used to determine the selectivity of each membrane toward nitrite over anions in the static mode. Selectivity

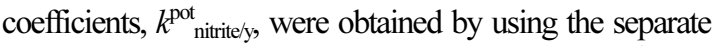
solution method at $0.01 \mathrm{M}$ standard solutions. ${ }^{26)}$

\section{Flow-Injection Analysis (FIA) Mode}

The arrangement shown in Fig. 2 was employed to evaluate the performance of the PVC- and sol-gel membrane electrodes in the FIA mode. A Phillips electrode body was fitted with a flow cap for use as a

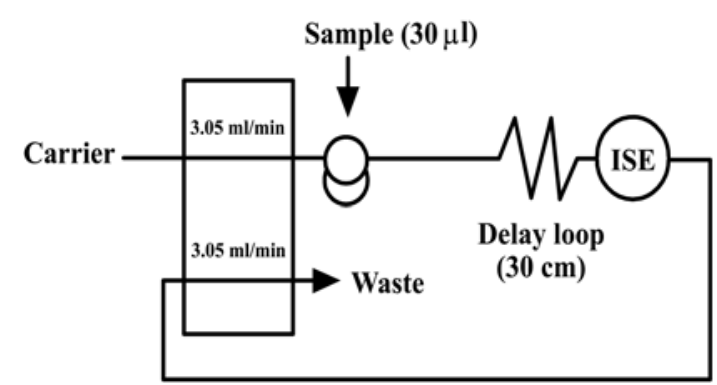

Fig. 2. Schematic of the sol-gel membrane electrode-based flow injection system.

flow-through detector in a large volume wall-jet cell. ${ }^{27)}$ Teflon tubing (0.012-in .d.) connected the flow cap to the injection valve. A peristaltic pump (Ismatech SA, Zurich) and a Rheodyne four-way rotary Teflon valve (Model 7125) equipped with a 30- $\mu \mathrm{L}$ sample loop completed the flow-injection setup. The MES buffer was used as the carrier stream. The nitrite-selective and $\mathrm{Ag} / \mathrm{AgCl}$ reference electrode were connected as described above.

\section{Results and Discussion}

A commercially available sol-state precursor, either tetraethylorthosilicate (TEOS) or tetramethylorthosilicate (TMOS), can be utilized to proceed the condensation reaction resulting in a glassy three-dimensional network structure (Fig. 3). These membranes are, however,

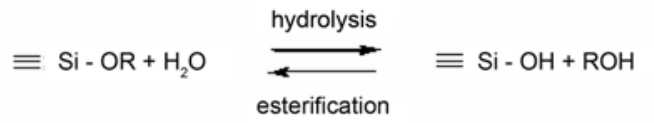

$$
\begin{aligned}
& \text { alcohol condensation } \\
& \equiv \mathrm{Si}-\mathrm{OR}+\mathrm{OH}-\mathrm{Si} \equiv \underset{\text { alcoholysis }}{\longrightarrow} \equiv \mathrm{Si}-\mathrm{O}-\mathrm{Si} \equiv+\mathrm{ROH} \\
& \text { water condensation } \\
& \equiv \mathrm{Si}-\mathrm{OH}+\mathrm{OH}-\mathrm{Si} \equiv \underset{\text { hydrolysis }}{\rightleftarrows} \equiv \mathrm{Si}-\mathrm{O}-\mathrm{Si} \equiv+\mathrm{H}_{2} \mathrm{O}
\end{aligned}
$$

Fig. 3. A general sol-gel process. 
too brittle to be implemented within typical membrane electrode bodies. In the present study, a precursor, 3, made from linkages between organic and inorganic components was employed as indicated in Fig. 1. Note that the organically modified precursor (1,4-precursor, 3 ) contains urethane moieties as well as silicates at both ends. As well known, the former relate to increased biocompatibility while the latter are compatible with glass. In the sol-gel applications for creating anion-selective membranes, however, the problems mainly relate to the precipitation of membrane components and cracking phenomena during gelling. Because of this, optimization the physical properties gel membranes were carried out. In the polymerization reaction, there are several reaction conditions to be taken into consideration: (1) Effect of an acid/base catalyst, (2) Use of a plasticizer, (3) Dependency on reaction temperature, (4) Aging.

First, the effects of the acid/base catalyst in the hydrolysis and condensation were studied (see Fig. 3). To prepare a single gel membrane, usually $150 \mathrm{mg}$ of the precursor was used in conjunction with DMF. To the mixture, $2 \mathrm{wt} \%$ porphyrin and an appropriate amount of TDMAC were added. Aqueous catalyst is then added $(15 \mu \mathrm{L})$. After vigorous shaking for $30 \mathrm{~s}$., the whole mixture was cast on PET boat $(15 \mathrm{~m} / \mathrm{m} \times$ $15 \mathrm{~m} / \mathrm{m})$. Earlier studies have revealed that acid-catalyzed condensations yield primarily linear or randomly branched polymers, while base-catalyzed ones tend to give highly branched clusters. ${ }^{28)}$ Clustering phenomena would obviously not be useful in order for a well-defined membrane to be made. This led to the use of an acid catalyst, $\mathrm{HCl}$. A previous report recommended that acid catalysts of $\mathrm{pH}$ lower than 2.5 should be employed for the polymerization of the traditional precursor, tetraethylorthosilicate (TEOS). ${ }^{28)}$ In this $\mathrm{pH}$ range, it was also found that hydrolysis is preferred while condensation is accelerated at relatively higher $\mathrm{pH}$ 's. In general, the condensation is known to be rate-determining. Redissolution (reverse reaction of the condensation) also accompanies usually the condensation. In the present study, different $\mathrm{pH}$ 's of $\mathrm{HCl}$ were tested. This is because an organically modified precursor rather than traditional TEOS was employed. Additional compounds such as a plasticizer, porphyrin, and TDMAC may hinder the polymerization and thus require a stronger catalyst. However, a low $\mathrm{pH}$ catalyst may cause the metalloporphyrin to lose its central metal. Tested concentrations ranged from $0.2 \mathrm{M}$ to $0.01 \mathrm{M}$. The lowest concentration for the reaction to yield a good membrane was $0.05 \mathrm{M}$
$\mathrm{HCl}$. If the concentration is higher, the reaction goes faster. However, the resulting membrane tends to brittle. If the concentration is lower than $0.05 \mathrm{M}$, much more time was required for the membrane to cure (ex. 1 week for $0.025 \mathrm{M}$ ) giving no apparent advantages.

Second, effects of a plasticizer on membrane physical properties were tested. In the case of the metalloporphyrin-doped films, the use of a plasticizer was required due to the porphyrin precipitation without the added plasticizer. The precipitate may cause the component to leach out from the membrane. Also a plasticizer seemed to impart good flexibility to the membrane. At first, NPOE was employed. NPOE, however, resulted in a turbid membrane. Turbidity commonly relates to precipitate formation. To solve the problem, ninety one plasticizers in a plasticizer sample kit (Scientific Polymer Products, Inc.) were tested. These include 7 adipates, 6 oleates, 4 chloroparaffins, 7 phosphates, and 16 phthalates. Among these, several candidates were found. These included tributyl and triphenyl phosphate, dimethyl phthalate, and n-butyl stearate. Among these, tributyl phosphate was chosen for further studies because the resulting membranes showed the best transparency as well as homogeneity (e.g., kimwipes didn't give any evidence of plasticizer exudation).

Third, dependency of membrane physical properties on reaction temperatures was examined. During the polymerization period, both hydrolysis and condensation (Fig. 3) must keep on going gradually building up a three-dimensional network. These processes are accelerated by heat, as the rate of both reactions increases as a function of temperature. ${ }^{29)}$ Temperatures ranging from $22^{\circ} \mathrm{C}$ to $65^{\circ} \mathrm{C}$ were thus tested for the sol-gel reaction. If the temperature was raised to $65^{\circ} \mathrm{C}$, there are more chances for the gel to crack. Membrane quality was quite acceptable when the films were processed at $40^{\circ} \mathrm{C}$.

Fourth, aging of gel membranes were considered, because this is a step for the condensation reactions to go forward to the right through the evaporation of ethanol and water (Fig. 3). This step will be crucial for creating a higher molecular weight cross-linked polymer. As the polymerization proceeds, condensation becomes a more time-consuming step. ${ }^{30)}$ DMF also evaporates slowly, leaving behind the gel structure. This is an important step, because, under harsh reaction conditions of temperature and/or strong catalyst acidity, membrane cracking may become a problem. This is due to the socalled capillary forces at the gel surface. To prevent 
this from happening, a "supercritical drying" method was suggested. ${ }^{31)}$ The resulting aerogel may render a gel with an enormous surface area. Indeed the large surface area and hydrophilic properties due to hydroxyl groups may provide unique membrane properties and thus applicability in our research. A temperature-controllable chamber with good vacuum capability may be required to further examine this area. In the present study, however, drying was performed without employing the supercritical drying. That is, as the membrane cured after $48 \mathrm{~h}$, the membrane was allowed to dry for at least one week in a vacuum oven at $48 \mathrm{mmHg}$ and $40^{\circ} \mathrm{C}$. Under these mild conditions, membrane cracking was minimized.

To examine the utility of the optimized sol-gel films, membranes with chloro(2,3,7,8,12,13,17,18-octaethylporphyrinato)indium(III) (In[OEP]Cl) and $\mathrm{Co}[\mathrm{TPP}] \mathrm{Cl}$ were prepared. Unfortunately, the $\mathrm{In}[\mathrm{OEP}] \mathrm{Cl}$ ) did not dissolve in DMF, prompting us to use $\mathrm{Co}[\mathrm{TPP}] \mathrm{Cl}$ for nitrite detection exclusively in this work. Use of DMF (or DMSO) is required to dissolve both the organic precursor and the ionophore as well as the aqueous acidic catalyst. The Co[TPP]Cl porphyrin was shown previously to function as a neutral carrier in a PVCbased membrane, requiring TDMAC as a cationic additive. ${ }^{8,9)}$ (see Table 1 for the membrane formulations.). Fig. 4 shows the calibration curves toward nitrite in MES buffer, $\mathrm{pH}$ 5.5, for the PVC- and sol-gel-based membrane electrodes: The sol-gel membranes seem to give somewhat sub-Nernstian responses (typically, 53 and $47 \mathrm{mV} /$ decade for $10 \%$ and $0 \%$ TDMAC membranes, respectively.). Although the numbers are lower than those of PVC-based ones (57-58 $\mathrm{mV} /$ decade), it was confirmed that the sol-gel membranes possess

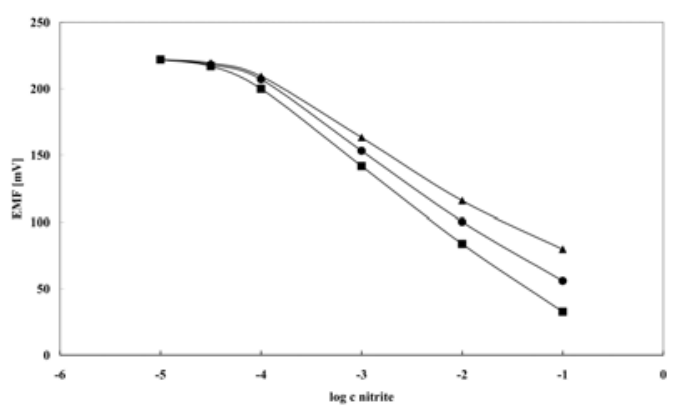

Fig. 4. Potentiometric response of electrodes constructed with a membrane: ( $\triangle$ ) PVC-10\%; ( O ) SG-10\%; ( $\square$ ) SG-0\% respectively (see Table 1 for the membrane ID). Baseline potentials are adjusted for comparison.
Table 2. Static mode potentiometric selectivity coefficients*, $\log \mathbf{k}^{\text {pot }}{ }_{\text {nitrite }}$ of Co[TPP]Cl-based electrodes prepared by the sol-gel method and a PVC-based electrode***

\begin{tabular}{cccc}
\hline Anion & $\mathrm{PVC}-10 \%$ & $\mathrm{SG} 1-10 \%$ & $\mathrm{SG}-0 \%$ \\
\hline $\mathrm{NO}_{2}^{-}$ & 0.0 & 0.0 & 0.0 \\
$\mathrm{Cl}^{-}$ & -3.2 & -2.0 & -1.5 \\
$\mathrm{Br}^{-}$ & $\mathrm{N} / \mathrm{A}$ & -1.8 & -1.5 \\
$\mathrm{NO}_{3}^{-}$ & -2.2 & -2.1 & -1.5 \\
salicylate & -0.9 & -1.0 & -1.0 \\
$\mathrm{SCN}^{-}$ & 1.0 & 1.1 & 0.8 \\
$\mathrm{ClO}_{4}^{-}$ & 0.1 & 0.1 & 0.1 \\
\hline
\end{tabular}

*Average of three determinations.

**Data for the PVC membrane electrode are adapted from ref. 8.

endogenous cationic sites, from the data obtained with $0 \%$ TDMAC membranes. Moreover, the selectivity coefficients of the sol-gel membrane electrodes were not quite as good as those of PVC-based ones especially with respect to chloride. As can be seen in Table 2, poorer selectivity over chloride was observed in the solgel membrane electrodes. It was interesting, however, that the two kinds of electrodes exhibited similar selectivity pattern toward more lipophilic anions such as salicylate. The selectivity pattern seems to arise from the inherent properties of the membrane. From the notion that the gels synthesized by TEOS are hydrophilic, ${ }^{32)}$ the organically modified sol-gel membranes are also believed to be more hydrophilic than PVC-based ones. Hydrophilicity of the gels synthesized from 1,4-precursors (or TEOS, TMOS) could be mainly due to the hydrogen bonding between the water adsorbate molecules and the unreacted hydroxyl groups of the precursor at the membrane surface. Obviously, these hydroxyl groups are generated by the hydrolysis of terminal alkoxides of the precursor. These results suggest that the applications of sol-gel membranes may be limited to the ionophores for hydrophilic anions/cations.

Although nitrite is not an analyte that is now measured routinely in clinical laboratories, there is great interest in developing new sensors for nitrite in the future that can function in biological samples, as a measure of nitric oxide (NO) production. Indeed, nitrite is often determined in plasma as a marker of NO production by endothelial cells. Hence, it would be interesting to examine the effect of proteins on the sol-gel based nitriteselective membrane developed here. Asymmetry potentials are found when a membrane electrode is in contact with protein-containing sample solutions (e.g., serum/ plasma samples). The proteins are adsorbed on the outer 


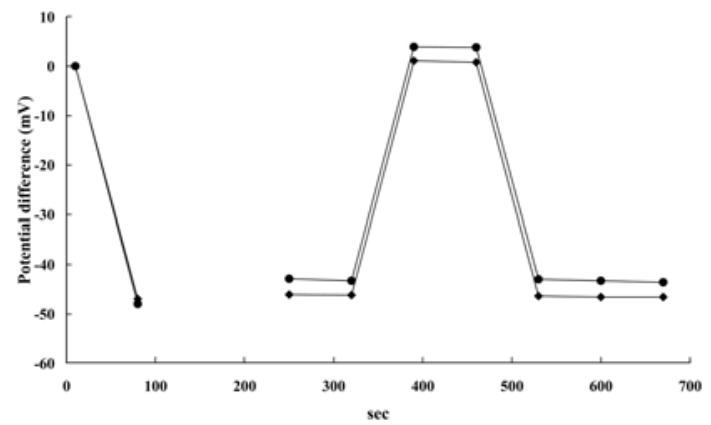

Fig. 5. Typical span changes of the PVC-10\% ( $)$ )and SG$10 \%(\diamond)$ membrane electrodes toward nitrite standards before and after the protein exposure (see Table 3 for experimental schedule.).

membrane surface. Because the adsorption is somewhat irreversible, it can result in a systematic error, causing a change in the cell constant $(\mathrm{K})$. This makes the reproducibility $(\% \mathrm{CV})$ of a replicate measurement poor. Membrane electrodes used here were examined in a flow injection arrangement (Fig. 2) and were the same membranes that were employed in the static mode experiments. Fig. 5 shows the tendency of span changes ( $\Delta \mathrm{mV}$ of two aqueous standards, 0.5 and $5 \mathrm{mM}$ nitrite) before and after the membrane electrodes were in contact with the $7 \mathrm{wt} . \%$ dialyzed albumin (refer to Table 3 for schedule). When the protein solution was flowed in between the aqueous nitrite standards(at the point of $150 \mathrm{~s}$ for $180 \mathrm{~s}$ ), there were clear differences in response behavior for the two kinds of electrodes, in terms of total response and the baseline potential. That is, baseline

Table 3. Time table used in the flow-injection tests for the alternate injection of aqueous nitrite standards and 7 wt.\% albumin solution

\begin{tabular}{cl}
\hline Time (s) & \multicolumn{1}{c}{ Injection schedule } \\
\hline 10 & $\mathbf{0 . 5} \mathrm{mM} \mathrm{NO}_{2}^{-}$standard \\
80 & $5 \mathrm{mM} \mathrm{NO}-$ standard \\
150 & 7 wt.\% dialyzed BSA in (carrier + buffer flow) \\
& for 180 sec: stop data aquisition for this period, \\
& then start to flow the MES buffer in (carrier + \\
& buffer flow) for 100 sec to wait for baseline return. \\
250 & $5 \mathrm{mM} \mathrm{NO}-$ standard \\
320 & $5 \mathrm{mM} \mathrm{NO}-$ standard \\
390 & $0.5 \mathrm{mM} \mathrm{NO}_{2}^{-}$standard \\
460 & $0.5 \mathrm{mM} \mathrm{NO}_{2}^{-}$standard \\
530 & $5 \mathrm{mM} \mathrm{NO} \mathrm{NO}_{2}^{-}$standard \\
600 & $5 \mathrm{mM} \mathrm{NO}-$ standard \\
670 & $5 \mathrm{mM} \mathrm{NO}-$ standard \\
\hline
\end{tabular}

potential for PVC membrane electrode shifted in the negative direction after the exposure to albumin. The amount of the shift was typically $5 \mathrm{mV}$, while the sol-gel membranes doped with the same ionophore showed less than a $1.2 \mathrm{mV}$ shift. These baseline shifts resulted in span changes in different ways for the two kinds of membranes. The significant span decrease of the PVC membrane electrodes immediately after the protein contact is mainly due to the shift in baseline. Although the span tends to be stabilized, on replicate measurements, this decreased span can give, especially for the first serum nitrite reading, a different value than it should (systematic error). Again, the less asymmetry potentials of the sol-gel membranes seem to be ascribed to the abovementioned hydrophilicity of the membrane surface.

\section{Conclusion}

A sol-gel encapsulation method was employed as the matrix to prepare potentiometric nitrite-selective membrane electrodes using $\mathrm{Co}[\mathrm{TPP}] \mathrm{Cl}$ as a neutral carrier. The organic-inorganic polymer membrane-based electrodes exhibited somewhat decreased slopes when compared to those of a traditional PVC-based one. While the sol-gel membrane showed less selectivity toward nitrite over hydrophilic chloride, selectivities over more lipophilic anions were quite comparable. Moreover, FIA experiments indicated that the sol-gel membranes are experiencing minimal and consistent asymmetry potentials when compared to the PVC-based ones.

\section{Acknowledgement}

SBP gratefully acknowledges financial support from Inje University(2006).

\section{References}

1. D. Ammann, M. Huser, B. Kräutler, B. Rusterholz, P. Schulthess, B. Lindemann, E. Halder, and W. Simon, "Anion selectivity of metalloporphyrins in membranes ", Helv. Chim. Acta, 69, 849 (1986).

2. N. A. Chaniotakis, A. M. Chasser, M. E. Meyerhoff, and J. T. Groves, "Influence of porphyrin structure on anion selectivities of manganese(III) porphyrin based membrane electrodes", Anal. Chem., 60, 185 (1988).

3. D. V. Brown, N. A. Chaniotakis, I. H. Lee, S. C. Ma, S. B. Park, M. E. Meyerhoff, R. J. Nick, and J. T. Groves, "Mn(III)-porphyrin-based thiocyanate-selective membrane electrodes: Characterization and application in flow injection determination of thiocyanate in saliva", Electroanalysis, 1 
477 (1989).

4. N. A. Chaniotakis, S. B. Park, and M. E. Meyerhoff, "Salicylate-selective membrane electrode based on tin(IV)tetraphenylporphyrin", Anal. Chem., 61, 566 (1989).

5. C. E. Kibbey, S. B. Park, G. DeAdwyler, and M. E. Meyerhoff, "Further studies on the potentiometric salicylate response of polymeric membranes doped with tin(IV)tetraphenylporphyrins", J. Electroanal. Chem., 335, 135 (1992).

6. S. B. Park, W. Matuszewski, M. E. Meyerhoff, Y. H. Liu, and K. M. Kadish, "Potentiometric anion selectivities of polymer membranes doped with indium(III)-porphyrins", Electroanalysis, 3909 (1991).

7. M. Huser, W. E. Morf, K. Fluri, K. Seiler, P. Schulthess, and W. Simon, "Transport Properties of anion-selective membranes based on cobyrinates and metalloporphyrin complexes as ionophores" Helv. Chim. Acta, 73, 1481 (1990).

8. E. Bakker, E. Malinowska, R. D. Schiller, and M. E. Meyerhoff, "Anion-selective membrane electrodes based on metalloporphyrins: The influence of lipophilic anionic and cationic sites on potentiometric selectivity" Talanta, 41, 881 (1994).

9. E. Malinowska, J. Niedziółka, and M. E. Meyerhoff, "Potentiometric and spectroscopic characterization of anion selective electrodes based on metal(III) porphyrin ionophores in polyurethane membranes", Anal. Chim. Acta, 432, 67 (2001).

10. E. Malinowska, L. Górski, and M. E. Meyerhoff, "This article is not included in your organization's subscription. However, you may be able to access this article under your organization's agreement with Elsevier. Zr(IV)-porphyrins as novel ionophores for fluoride-selective polymeric membrane electrodes", Anal. Chim. Acta, 468, 133 (2002).

11. E. D. Steinle, S. Amemiya, P. Bühlmann, and M. E. Meyerhoff, "Origin of non-Nernstian anion response slopes of metalloporphyrin-based liquid/polymer membrane electrodes", Anal. Chem., 72, 5766 (2000).

12. S. Oka, Y. Sibazaki, and S. Tahara, "Direct potentiometric determination of chloride ion in whole blood", Anal. Chem., 53, 588 (1981).

13. C. J. Brinker and G. W. Scherer, "Sol-Gel Science", Chapter 14, Academic Press, San Diego (1990).

14. F. L. Dickert and O. Hayden, "Bioimprinting of polymers and solgel phases. selective detection of yeasts with imprinted polymers", Anal. Chem., 74, 1302 (2002).

15. Y. Tang, E. C. Tehan, Z. Tao, and F. V. Bright, "Solgelderived sensor materials that yield linear calibration plots, high sensitivity, and long-term stability", Anal. Chem., 75, 2407 (2003)

16. K. Kimura, S. Yajima, H. Takase, M. Yokoyama, and Y.
Sakurai, "Solgel modification of $\mathrm{pH}$ electrode glass membranes for sensing anions and metal ions", Anal. Chem., 73, 1605 (2001).

17. W. Kim, S. Chung, S. B. Park, S. C. Lee, C. Kim, and D. D. Sung, "Solgel method for the matrix of chlorideselective membranes doped with tridodecylmethylammonium chloride", Anal. Chem., 69, 95 (1997).

18. W. Kim, D. D. Sung, G. S. Cha, and S. B. Park, "Chloride-selective membranes prepared with different matrices including polymers obtained by the sol-gel method", Analyst, 123, 379 (1998).

19. B. H. Lee, Y. B. Shim, and S. B. Park, "A lipophilic solgel matrix for the development of a carbonate-selective electrode", Anal. Chem., 76, 6150 (2004).

20. W. Lizinsky, "Toxicity of N-nitroso compounds", Cambridge University Press, Cambridge (1992).

21. R. W. Boubel, D. L. Fox, D. B. Turner, and A. C. Stern, "Fundamentals of Air Pollution", Academic Press, San Diego (1994).

22. J. A. Dean, "Analytical Chemistry Handbook", 1, McGraw Hill, New York (1995).

23. I. H. A. Badr, "Nitrite-selective optical sensors based on organopalladium ionophores", Analytical Letters, 34, 2019 (2001).

24. S. S. Eaton and G. R. Eaton, "Rotation of phenyl rings in metal complexes of substituted tetraphenylporphyrins", $J$. Am. Chem. Soc., 97, 3660 (1975).

25. U. Wuthier, H. Pham, R. Zuend, D. Welti, R. Funck, A. Bezegh, D. Ammann, E. Pretsch, and W. Simon, "Tin organic compounds as neutral carriers for anion selective electrodes", Anal. Chem., 56, 535 (1984).

26. E. Bakker, E. Pretsch, and P. Bühlmann, "Selectivity of potentiometric ion sensors", Anal. Chem., 72, 1127 (2000).

27. M. Trojanowicz and M. E. Meyerhoff, "Potentiometric $\mathrm{pH}$ detection in suppressed ion chromatography", Anal. Chem., 61, 787 (1989).

28. A. C. Pierre (Ed), "Introduction to sol-gel processing", pp. 57-66, Kluwer Academic Publishers, Boston (1998).

29. K. Kamiya, M. Ohya, and T. Yoko, "Nitrogen-containing $\mathrm{SiO}_{2}$ glass fibers prepared by ammonolysis of gels made from silicon alkoxides", J. of Non-Cryst. Solids, 83, 208 (1986).

30. Y. A. Attia (Ed), "Sol-gel processing and applications" pp. 3-16., Plenum Press, New York (1994).

31 S. S. Kistler, "Coherent Expanded Aerogels and Jellies", Nature, 127, 741 (1931).

32. V. C. Menon, S. Komarneni, M. Park, M. Schmuecker, and H. Schneider, "Synthesis of hydrophilic and hydrophobic high surface area xerogels at $\mathrm{pHs}$ below silica isoelectric point", J. of Sol-Gel Sci. and Tech., 11, 7 (1988). 